\title{
OPTIMIZATION OF MICROWAVE ASSISTED HYDRODISTILLATION OF LEMONGRASS (CYMBOPOGON CITRATUS) USING RESPONSE SURFACE METHODOLOGY
}

\author{
Ranitha M1, Abdurahman H. Nour ${ }^{2}$, Ziad A. S ${ }^{3}$, Azhari H. $N^{4}$, ThanaRaj $S^{5}$
}

\begin{abstract}
This research deals with the optimization of microwave assisted hydrodistillation (MAHD) of Lemongrass (cymbopogon citratus) by using response surface methodology. The constituents of extracted oil using MAHD was compared with the one obtained by conventional hydrodistillation (HD). The major constituent found in both extracts was citral, however with more abundant amount in MAHD. Central composite design (CCD) has been employed for evaluate the effect of water to plant material ratio, microwave power level and extraction time. The design model predicted the optimum yield of $1.4612 \%$ at water to plant material ratio of $8: 1$, $250 \mathrm{~W}$ microwave power level and 90 min of extraction time. ANOVA results show the model was significant as indication from $R^{2}$ and $F$ value of 0.95 and 29.78, respectively. The yield obtained under the proposed economic condition in the laboratory (1.4635\%) was very close with the predicted one, proved the reliability of the employed model, as well as the success of the RSM in optimizing the extraction conditions.
\end{abstract}

Keywords: Microwave, MAHD, HD, Lemongrass, RSM, yield

\section{INTRODUCTION}

Essential oils are natural products obtained from plants. It is estimated that the global number of plants is of the order of 300,000 and about $10 \%$ of these contains essential oils and could be used as a source for their production (Husnu and Gerhard, 2010). Their extracts are formed by combination of diverse and complex volatile mixtures of chemical compounds, with predominance of terpene associated to aldehydes, alcohols, and ketones which were accumulated in various structure of the plant (Tajidin et al., 2011) The use of medicinal plants extracts is part of a competitive market, which includes pharmaceuticals, food, cosmetics, and perfumery markets, mainly to use their active substance. China and India play a major role followed by Indonesia, Sri Lanka, and Vietnam with (Husnu.K. and Gerhard.B., 2010).

Lemongrass (Cymbopogon Citratus), a perennial plant with long, thin leaves, is one of the largely cultivated medicinal plants for its essential oils in parts of tropical and subtropical areas of Asia, Africa and America ( Chanthal et.al., 2012). The leaves of Lemongrass (Cymbopogon Citratus) present lemony characteristic flavor due to its main content, citral which present great importance to the industry. Citral, a combination of neral and geranial isomers, is used as a raw material for the production of ionone, vitamin A and beta-carotene (Carlson, 2001). There were a number of studies carried out to prove the anti-oxidant, anti-microbial and anti-fungal activities of Lemongrass (Cymbopogon Citratus) (Asaolu, 2009; Behboud et al., 2012; Nikos and Costas ,2007).
The common methods to extract essential oil from medicinal plant, including for Lemongrass (Cymbopogon Citratus), are hydrodistillation (HD), steam distillation, steam and water distillation, maceration, empyreumatic (or destructive) distillation and expression (Abderrahmane et al., 2013). In contrast, these common methods can induce thermal degradation, hydrolysis and water solubililization of some fragrance constituents. In addition, the oil obtained through solvent aided extraction contains residues that pollute the foods fragrances to which they are added. As a means to overcome this sort of drawbacks, an advance and improved method such as microwave-assisted extraction (Hong et al, 2010), ohmic-assisted hydrodistillation (Mohsen et al., 2012), subcritical water extraction (Mohammad et al, 2007) and ultrasound-assisted extraction (Porto et al., 2009) have been applied to shorten extraction time, improve the extraction yield and reduce the operational costs.

Recently, microwave-assisted hydrodistillaton (MAHD), procedures for isolating essential oils, have become attractive for use in laboratories and industry due to its effective heating, fast energy transfer and also an environmental friendly extraction technique. Its acceptance as potential and powerful alternative for conventional extraction techniques has been verified through several researches (Jila et al., 2012a; Abderrahmane et al., 2013; Mohammad and Karamatollah, 2008). Moreover, the low content of essential oil in plant materials need an extraction technique with a high performance to achieve higher yields, thus parameter optimization of that particular technique is the most vital 
process to achieve this. Response surface methodology (RSM) is a combination of mathematical and statistical technique effective for responses that are influenced by various factors and their interactions, (Myers, 2002). There were a number of researches has been conducted in optimisation of lemongrass essential oil extraction using Supercritical Carbon Dioxide (Huynh et al., 2008), Pressurized Liquid Extraction (Nur et al., 2013) and Ohmic Heated Hydrodistillation ( Muhammad et al., 2012). However, to the best of this author's knowledge, the optimization of the Microwave-assisted hydrodistillation of oil from Lemongrass using response surface methodology (RSM) has not been reported yet. In this study, CentralComposite design (CCD) is applied to investigate the effects of extraction time, microwave power and water to plant material ratio on the yield of Lemongrass oil extracted by Microwave assisted hydrodistillation under the applied experimental range.

\section{MATERIALS AND METHOD}

\subsection{Plant Samples}

Lemongrass (Cymbopogon Citratus) leaves were collected from home garden in northwest of Malaysia. According to Edwin et al., 2012, for Lemongrass (Cymbopogon Citratus), the percentage essential oil yield for the partially dried leaves was found to be higher than that of the fresh leaves. Thus, once collected, the plant material were dried at room temperature for a week then kept in a sealed plastic bag at ambient temperature and protected from the light. The samples were ground using a kitchen grinder (Super Blender,Panasonic, Tokyo, Japan) at room temperature prior to extraction.

\subsection{Reagents}

Anhydrous sodium sulfate and n-hexane used was analytical grade reagent purchased from Sigma Aldrich (US) and Fisher Scientific (US), respectively. Deionised water used was purified by Milli-Q purification system (Millipore) (Massachusetts, USA).

\subsection{Microwave-Assisted Hydrodistillation}

A modified domestic microwave oven model Samsung MW71E connected to the Clevenger apparatus was modified for MAHD operation. A Schematic diagram of this extraction system were shown in Fig.1.The Samsung MW71E has 1150 Watt power consumption, 800 Watt output power with $250 \mathrm{v}$ $50 \mathrm{~Hz}$ power soure; $2450 \mathrm{MHz}$. The cavity dimensions of the microwave oven were 306 × 211 x $320 \mathrm{~mm}$. The microwaveassisted hydrodistillation were conducted at water to raw material ratio of $6: 1,8: 1$ and $10: 1$ at 200, 225 and $250 \mathrm{~W}$ microwave power for durations of $30,60,90$ and $120 \mathrm{~min} .2 \mathrm{~h}$ of extraction is sufficient enough to extract essential oil from the sample through MAHD (Mohammad and Karamatollah, 2008). The flask containing $50 \mathrm{~g}$ of Lemongrass
(Cymbopogon Citratus) with its distilled water was placed within the microwave oven cavity. A condenser which has been set on the top, outside the oven, was used to collect the extracted essential oils.

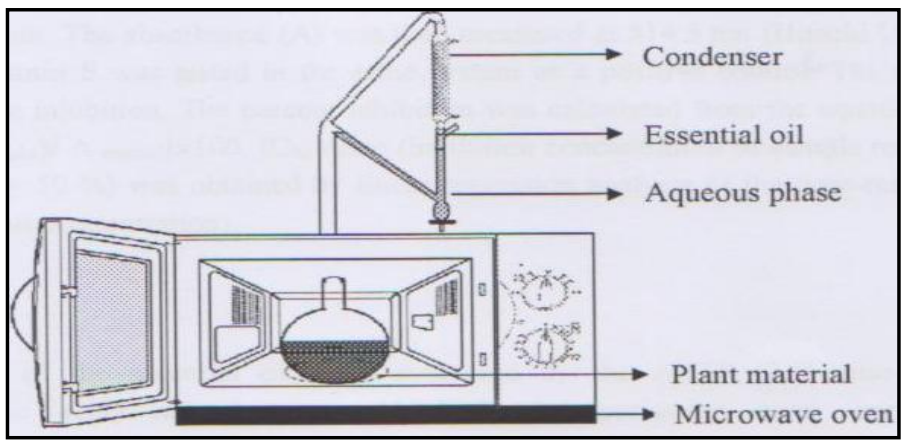

Fig 1: Schematic Diagram of Microwave-Assisted Hydrodistillation method

\subsection{Hydrodistillation}

$50 \mathrm{~g}$ of fresh Lemongrass (Cymbopogon Citratus) leaves were placed in a $1 \mathrm{~L}$ flask containing $400 \mathrm{ml}$ of distilled water and hydrodistilled for 30, 60, 90, 120 and150 min using a Clevenger-type apparatus. The system was operated at a fixed power of $500 \mathrm{~W}$ and under atmospheric pressure (Liu et al., 2012).

\subsection{Analysis of Sample}

To remove water, the collected extracts were dried over anhydrous sodium sulfate, weighed and stored in vial at $+4 \mathrm{oC}$ prior to analysis. The amount of yield obtained from the extraction was analyzed to evaluate the performance of MAHD in Lemongrass (Cymbopogon Citratus) oil extraction. Yield of oil that obtained for every run was calculated by using Equation (1):

$$
\begin{aligned}
& \text { Yield of essential oil } \\
& =\frac{\text { amount of essential oil }(\mathrm{g}) \text { obtained }}{\text { amount of raw materials }(\mathrm{g}) \text { used }}
\end{aligned}
$$

A GC-MS instrument (5973N, Agilent Technologies, Wilmington, DE, UAS) equipped with a mass selective detector operating in the electron impact mode $(70 \mathrm{eV})$ was used to study the composition of the essential oil at extracted various group of parameter condition to analyze its quality. The GC part $(6890 \mathrm{~N}$, Agilent Technologies, Palo Alto, CA, USA) was equipped with an HP-5MS (Agilent BTechnologies) capillary column $(15 \mathrm{~m}$ x $0.25 \mathrm{~mm} ; 0.25 \mu \mathrm{m}$ fil thickness). The injector temperature was set 200 and column temperature was set initially at 40 and then programmed at 8 /min to 240 . The interface temperature was set as 250 while the source temperature 200. This was an optimized temperature program. The samples were diluted with n-hexane $(1 / 10, v / v)$ and a volume of $1.0 \mu \mathrm{l}$ was injected to the GC with 
the injector in the split mode (split ratio: 1/10). Carrier gas, $\mathrm{He}$, was adjusted to a linear velocity of $1 \mathrm{ml} \mathrm{min-1} \mathrm{(Edwin} \mathrm{et}$ al., 2012).

\subsection{Experimental Design}

A $3^{3}$ central composite design from RSM was used to determine the optimal factors of MAHD to extract oil from Lemongrass (Cymbopogon citratus). The three independent variables namely water to plant material ratio (6:1 - 10:1, A), microwave power level (200W - 250W, B), and extraction time $(60-120, C)$, as presented in Table 1, were being studied for their influence on extraction yield. The statistical software, Design Expert 7.1.6 was employed to carried ANOVA analysis, regression coefficient calculation and projection of the experimental data in graphical mode (response surface and contour plot). In order to verify the adequacy of the model developed, the experimental value and predicted values were compared.

Table 1: Design summary

\begin{tabular}{|c|c|c|c|c|c|c|}
\hline Factors & Name & Units & Low Actual & High Actual & Low Coded & High Coded \\
\hline A & Water to plant material ratio & & $6: 1$ & $10: 1$ & -1 & 1 \\
\hline B & Microwave power level & watt & 250 & 200 & -1 & 1 \\
\hline C & Extraction Time & min & 60 & 120 & -1 & 1 \\
\hline
\end{tabular}

\section{RESULTS AND DISCUSSION}

\subsection{Effect of Process Parameters}

Effect of water to plant material ratio-The effect of different water to raw material ratio of $6: 1,8: 1$ and $10: 1$ on yield of Lemongrass (Cymbopogon citratus) by using HD and MAHD (250W) was being presented in Figure 2 and 3, respectively. Both methods had illustrated similar output pattern on the variability of water to raw material ratio where by decreasing the water to plant material ratio from 10:1 to 8:1, the highest extracted oil yield (w/w) increased from $1.29 \%$ to $1.48 \%$ and $1.19 \%$ to $1.38 \%$ in MAHD and HD, respectively. However, the extracted oil yield (w/w) decreased to $0.90 \%$ in MAHD and to $0.98 \%$ in HD, when the ratio is reduced to $6: 1$. This was because, when the ratio of solvent increased from 6:1 to 8:1 Lemongrass (Cymbopogon citratus) oil were extracted fully with the rise of the driving force for the mass transfer (Lan et al., 2013). However, the yield obtained started to decline when the ratio further increased to 10:1 since the excess amount of water caused thermal stress due to rapid heating of the solution on account of effective absorption of microwaves by water (Mahaveer et al., 2009). Therefore it is important to identify the optimum level of water in the distillation system to avoid the reverse act of the water.

Effect of Microwave Power-As being illustrated in Figure 4, the initial extraction rate increased with increase in microwave power where the yield being obtained up to $90 \mathrm{~min}$ were $1.21 \%, 1.34 \%$ and $1.46 \%$, respectively. However, when the extraction solutions were heated long enough, more than 90 min, the yields under different power were almost similar. This is doubtlessly due to the rapid generation of heat inside the immersed Lemongrass (Cymbopogon Citratus) with the absorption of microwave energy and the subsequent formation of a higher pressure gradient inside the plant material when subjected to higher microwave power levels which cause the essential oil to be released out of the glands quicker (Ferhat et al., 2006). The obtained result is in accordance with Jila et al (2012b.) finding on effect of microwave power on extraction of Echinophora platyloba DC using MAHD.

Effect of Extraction Time-Figure 5 shows the influence of extraction time on the extraction yields of Lemongrass (Cymbopogon Citratus) over the range 30-120 min under a fix microwave power of $250 \mathrm{~W}$ and water to raw material ratio of 8:1. As being depicted in fig. 5, most of the oil was being extracted within 30 to 90 minutes and the amount of yield obtained up to this period was $1.46 \%$. However, further increase in extraction time resulted in no significant improvement in the extraction performance. In general, the rate of extraction was high at the beginning of the extraction but get slow gradually by time. The effect of this parameter in MAHD has been studied by number researches on various plant materials, (Muhammad et al., 2012; Mohammad and Karamatollah, 2008; Jila et al., 2012a), and almost all of them obtained the same configuration as illustrated in Figure 5. These results confirmed the Fick's second law of diffusion which stated about the final equilibrium achieved by the solute concentrations in plant matrix and in the solvent after a certain time. This caused into no significant improvement in oil yield when prolonging the extraction time. 


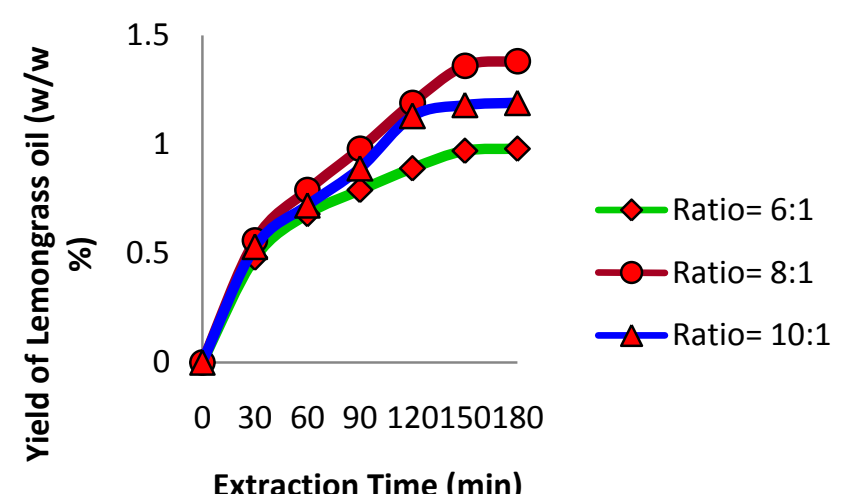

Fig 2: Effect of extraction time and ratio of plant material to water on Lemongrass (Cymbopogon citratus) yield being extracted by HD

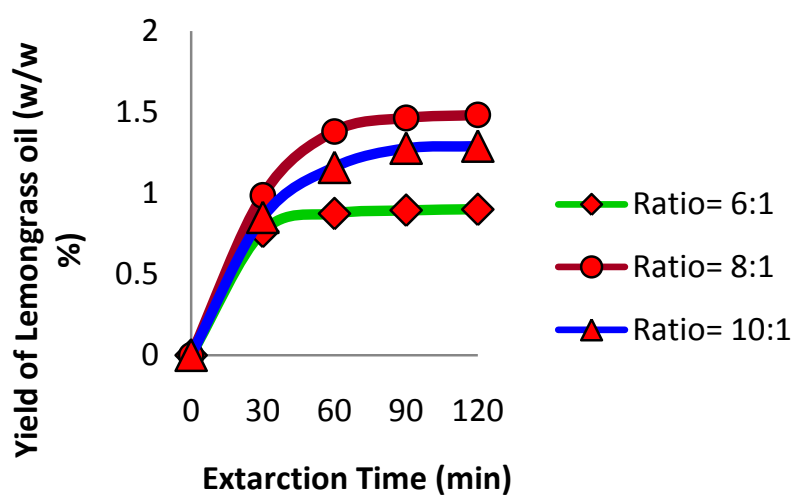

Fig 3: Effect of extraction time and ratio of plant material to water on Lemongrass (Cymbopogon citratus) oil yield being extracted by $250 \mathrm{~W}$ of MAHD

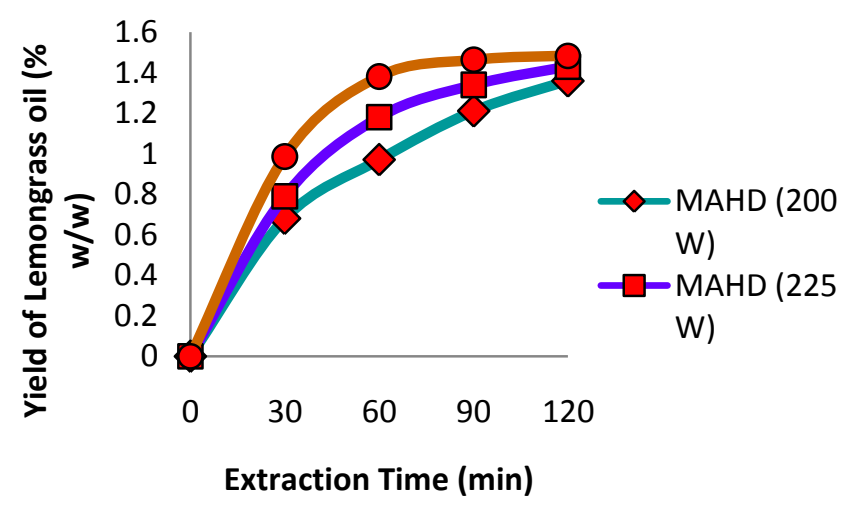

Fig 4: Effect of extraction time and different microwave power level on Lemongrass (Cymbopogon citratus) oil yield in water to plant material ratio of $8: 1$

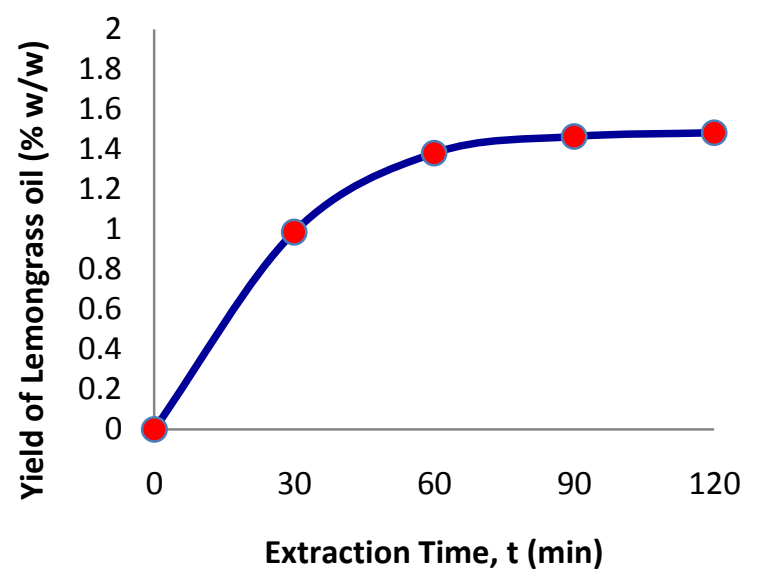

Fig 5: Effect of extraction time on Lemongrass (Cymbopogon citratus) oil yield being extracted by $250 \mathrm{~W}$ of MAHD in water to raw material ratio of $8: 1$

\subsection{Comparison of Lemongrass (Cymbopogon Citratus) oil obtained by Conventional \\ Hydrodistillation Method}

To evaluate the effect of microwave in the extraction of essential oil, the results of MAHD, at optimal conditions, were compared with those of conventional hydrodistillation (HD) in term of the oil yield and its constituents. HD is an accepted method that is used as reference for the quantification of essential oils (Sibel et al., 2012).

The induction time for MAHD was only 18 minutes whereas for HD it was 30min. This show, $30 \%$ of the total oil can be extracted using MAHD by the time the extraction of essential oil by HD started. It is interesting to note that, the amount of yield extracted by MAHD after $60 \mathrm{~min}$ will similar as the oil resulted after 180 min by HD. At 90 min of extraction, the oil yield by MAHD and HD method were $1.46 \%$ and $0.98 \%$, respectively. The ultimate yield of essential oil by MAHD after $2 \mathrm{~h}$ of extraction was higher than that obtained by HD after $3 \mathrm{~h}$ of extraction $(1.48 \%$ vs. $1.38 \%, w / w)$. This momentous heating rate is due to the microwaves which deliver bulk heating within the system leads to a substantial saving in time by using MAHD. Unlike the classical conductive heating methods, microwave could distribute heat to the entire sample almost simultaneously and at a higher rate (Beatrice and Philippe, 2002). The movement of the microwaves through the sample generates heat internally as well as at the surface of the treated and this known as bulk heating mechanism. Whereas in HD, heat only applies on the surface and too high temperature could cause sample burning easily. Besides, HD processing time is slow due to thermal conductivity of the fluids. 
GC-MS analyses were performed with the aim to compare the compositions of the Lemongrass (Cymbopogon Citratus) oil extracted by MAHD and HD. The comparison of major compounds found in their optimized condition, neral, geranial and myrcene, and some minor components are shown in Table 2. Citral, the combination of the neral and geranial isomers, is the key compound to evaluate the quality of Lemongrass (Cymbopogon Citratus) oil. From the results, it was observed that concentration of key compound found in the Lemongrass (Cymbopogon Citratus) oil were almost similar for both methods. Moreover, the oil compositions revealed that higher amounts of oxygenated monoterpenes (citral) were presented in the essential oil isolated by MAHD and less in HD. Whereas, vice versa was happened in the case of $\beta$-myrcene content. This difference could be attributed to the microwave radiation effect. It would be reasonable to believe that for the more polar compounds the more readily the microwave irradiation is absorbed, the better the interaction between the electromagnetic wave and matters is established, and the more polar aromatic components are obtained. All these results have proved that microwave greatly accelerated the extraction process, but without causing significant affect in the volatile oil composition and even produce essential oil with more preferable quality.

By considering the chemical profile of the essential oil of Lemongrass (Cymbopogon citratus) from northwest of Malaysia and reports of other scientist, it shows there are significant quantitative differences between the chemical profiles of the major components of the essential oil (Mohamed, et al.,2012; Chanthal et al., 2012; Tajidin et al., 2012). According to Jila et al., 2012b, these variations may due to the diverse climatic and geographic differences and at the same time to different harvesting times and extraction procedures.

Table 2: Composition of Lemongrass (Cymbopogon citratus) oil extracted by MAHD and HD

\begin{tabular}{|l|c|c|}
\hline \multirow{2}{*}{ Compound } & \multicolumn{2}{|c|}{ Relative peak area (\%) } \\
\cline { 2 - 3 } & MAHD & HD \\
\hline$\beta$-Myrcene & 3.69 & 5.54 \\
\hline Neral $^{\mathrm{a}}$ & 35.55 & 36.65 \\
\hline Geranial $^{\mathrm{b}}$ & 51.43 & 46.85 \\
\hline Citral $^{\text {ab }}$ & 86.98 & 83.50 \\
\hline Geranic acid $^{\prime}$ & 1.81 & 2.16 \\
\hline Linalool & 0.78 & 0.65 \\
\hline Geraniol & 3.94 & 4.21 \\
\hline
\end{tabular}

\subsection{Optimization of MAHD Parameters}

Table 3 presents the CCD matrix and the oil yield obtained for each experimental run. In order to ensure a good model for the response, three tests needs to be performed which is significance of the regression model, significance on individual coefficients and lack-of-fit. Table 4 shows the ANOVA table for the response surface of quadratic model for Lemongrass (Cymbopogon citratus) oil yield which compromise all tests stated above. The Model F-value of 26.96 implies the model is significant. The values of "Prob > F or p-value" in Table 4 for the model was less than 0.05 indicated that the model was significant. In a similar manner, the main effect of water to plant material ratio (A), main effect of microwave power level (B), main effect of extraction time (C), the two level interactions of microwave power level and extraction time (BC), the second order effect of the water to plant material ratio $\left(\mathrm{A}^{2}\right)$, the second order effect of microwave power level $\left(\mathrm{B}^{2}\right)$ and the second order effect of the extraction time $\left(\mathrm{C}^{2}\right)$ were significant model terms. Other model terms whose values were greater than 0.1000 might be said to be not significant. The insignificant terms could be removed and may result in an improved model. The results of the reduced quadratic model were still being indicated that the model was still significant (Table 5). Among the significant model terms which were $\mathrm{A}, \mathrm{B}, \mathrm{C}, \mathrm{BC}, \mathrm{A}^{2}, \mathrm{~B}^{2}$ and $\mathrm{C}^{2}$, the main effect of water to plant material ratio (A) was the most significant factor being associated with yield of Lemongrass (Cymbopogon citratus) oil since water has polar nature which could interact abundantly with microwaves, thus, largely influence the efficiency of microwave extraction. This finding is in agreement with the finding of Xiaofeng et al., (2013) and Zhu et al., (2012). The significant factors were being ranked based on the value of F-value. Therefore, in this study, the ranking of the significances of the factors are as follows: $\mathrm{A}>$ $\mathrm{A}^{2}>\mathrm{C}^{2}>\mathrm{C}>\mathrm{B}>\mathrm{BC}>\mathrm{B}^{2}$.

The "Lack-of-Fit F-value" of 1.69 implies the Lack of Fit was not significant relative to the pure error. This was desirable as wanted a model that fits. There was a $31.59 \%$ chance that a "Lack of Fit F-value" this large could occur due to noise. In general, $\mathrm{R}^{2}$ is being used to decide whether a regression model is appropriate. In current study, the $\mathrm{R}^{2}$-value being calculated was 0.95 , reasonably close to 1 , which is acceptable. The predicted $\mathrm{R}^{2}$ of 0.8219 was in reasonable agreement with the adjusted $\mathrm{R}^{2}$ of 0.9180 . Adequate precision compares the range of the predicted values at the design points to the average prediction error. A ratio greater than 4 is desirable (Cochran, 1992). In this case, the value was well above 4 where the ratio of 18.029 indicated an adequate signal. This model could be used to navigate the design space. 
Table 3: Fractional factorial design with uncoded independent variables and corresponding response for MAHD

\begin{tabular}{|c|c|c|c|c|}
\hline \multirow{2}{*}{ Standard order no. } & \multicolumn{3}{|c|}{ Experimental Parameters } & \multirow{2}{*}{ Yield, (\%w/w) } \\
\cline { 2 - 4 } & $\begin{array}{c}\text { Water to plant } \\
\text { material ratio, A }\end{array}$ & $\begin{array}{c}\text { Microwave power } \\
\text { level, B }\end{array}$ & Extraction time,C \\
\hline 1 & 6.00 & 200.00 & 60.00 & 0.58 \\
\hline 2 & 10.00 & 200.00 & 60.00 & 0.89 \\
\hline 3 & 6.00 & 250.00 & 60.00 & 1.16 \\
\hline 4 & 10.00 & 250.00 & 60.00 & 0.79 \\
\hline 5 & 6.00 & 200.00 & 120.00 & 0.34 \\
\hline 6 & 10.00 & 200.00 & 120.00 & 1.29 \\
\hline 7 & 6.00 & 250.00 & 120.00 & 1.4612 \\
\hline 8 & 10.00 & 250.00 & 120.00 & 1.42 \\
\hline 9 & 8.00 & 225.00 & 90.00 & 1.34 \\
\hline 10 & 8.00 & 225.00 & 90.00 & 1.38 \\
\hline 11 & 8.00 & 225.00 & 90.00 & 1.13 \\
\hline 12 & 8.00 & 225.00 & 90.00 & 1.276 \\
\hline 13 & 6.00 & 225.00 & 90.00 & 1.49 \\
\hline 14 & 11.00 & 225.00 & 90.00 & 0.79 \\
\hline 15 & 8.00 & 200.00 & 90.00 & 1.44 \\
\hline 16 & 8.00 & 275.00 & 90.00 & 1.34 \\
\hline 17 & 8.00 & 225.00 & 30.00 & 1.46 \\
\hline 18 & 8.00 & 225.00 & 140.00 & \\
\hline 19 & 8.00 & 225.00 & 90.00 & 90.00 \\
\hline 20 & 8.00 & 225.00 & & 9 \\
\hline
\end{tabular}

Table 4: ANOVA table (partial sum of square) for quadratic model (response: Yield of Lemongrass Oil)

\begin{tabular}{|c|c|c|c|c|c|c|}
\hline Source & $\begin{array}{c}\text { Sum of } \\
\text { Squares }\end{array}$ & $\mathbf{d F}$ & Mean Square & F Value & $\begin{array}{c}\text { P-Value }(P> \\
\text { F) }\end{array}$ & \\
\hline Model & 1.29 & 9 & 0.14 & 26.96 & $<0.0001$ & significant \\
\hline A-Water Ratio & 0.37 & 1 & 0.37 & 70.24 & $<0.0001$ & \\
\hline B-Microwave Power & 0.064 & 1 & 0.064 & 12.09 & 0.0070 & \\
\hline C-Extraction Time & 0.20 & 1 & 0.20 & 38.21 & 0.0002 & \\
\hline $\mathrm{AB}$ & 0.004297 & 1 & 0.004297 & 0.81 & 0.3916 & \\
\hline $\mathrm{AC}$ & 0.015 & 1 & 0.015 & 2.80 & 0.1283 & \\
\hline $\mathrm{BC}$ & 0.032 & 1 & 0.032 & 6.01 & 0.0367 & \\
\hline $\mathrm{A}^{2}$ & 0.36 & 1 & 0.36 & 66.95 & $<0.0001$ & \\
\hline $\mathrm{B}^{2}$ & 0.030 & 1 & 0.030 & 5.63 & 0.0417 & \\
\hline $\mathrm{C}^{2}$ & 0.24 & 1 & 0.24 & 45.17 & $<0.0001$ & \\
\hline Residual & 0.048 & 9 & 0.005305 & & & \\
\hline Lack of Fit & 0.032 & 5 & 0.006480 & 1.69 & 0.3159 & not significant \\
\hline Pure Error & 0.015 & 4 & 0.003836 & & & \\
\hline Cor Total & 1.47 & 19 & & & & \\
\hline Std. Dev & 0.073 & & $\mathrm{R}^{2}$ & 0.9642 & & \\
\hline \multirow[t]{3}{*}{ Mean } & 1.19 & & Adj $R^{2}$ & 0.9285 & & \\
\hline & & & Pred $\mathrm{R}^{2}$ & 0.8271 & & \\
\hline & & & Adeq Precision & 17.094 & & \\
\hline
\end{tabular}


Table 5: ANOVA table (partial sum of square) for reduced quadratic model (response: Yield of Lemongrass Oil)

\begin{tabular}{|c|c|c|c|c|c|c|}
\hline Source & $\begin{array}{c}\text { Sum of } \\
\text { Squares }\end{array}$ & $\mathbf{d F}$ & Mean Square & F Value & $\begin{array}{c}\text { P-Value (P } \\
>\text { F) }\end{array}$ & \\
\hline Model & 1.27 & 7 & 0.18 & 29.78 & $<0.0001$ & significant \\
\hline A-Water Ratio & 0.37 & 1 & 0.37 & 61.25 & $<0.0001$ & \\
\hline B-Microwave Power & 0.064 & 1 & 0.064 & 10.54 & 0.0078 & \\
\hline C-Extraction Time & 0.20 & 1 & 0.20 & 33.32 & $<0.0001$ & \\
\hline $\mathrm{BC}$ & 0.032 & 1 & 0.032 & 5.24 & 0.0428 & \\
\hline $\mathrm{A}^{2}$ & 0.36 & 1 & 0.36 & 58.38 & $<0.0001$ & \\
\hline $\mathrm{B}^{2}$ & 0.030 & 1 & 0.030 & 4.91 & 0.0487 & \\
\hline $\mathrm{C}^{2}$ & 0.24 & 1 & 0.24 & 39.39 & $<0.0001$ & \\
\hline Residual & 0.067 & 11 & 0.006084 & & & \\
\hline Lack of Fit & 0.052 & 7 & 0.007368 & 1.92 & 0.2756 & not significant \\
\hline Pure Error & 0.015 & 4 & 0.003836 & & & \\
\hline Cor Total & 1.47 & 19 & & & & \\
\hline Std. Dev & 0.078 & & $\mathrm{R}^{2}$ & 0.9499 & & \\
\hline \multirow[t]{3}{*}{ Mean } & 1.19 & & Adj $R^{2}$ & 0.9180 & & \\
\hline & & & Pred $\mathrm{R}^{2}$ & 0.8219 & & \\
\hline & & & Adeq Precision & 18.029 & & \\
\hline
\end{tabular}

The final model in terms of coded factors was being presented as follows:

Yield of Lemongrass (Cymbopogon citratus) Oil, Y:

$$
\begin{gathered}
\mathrm{Y}=1.43+0.19 * \mathrm{~A}+0.079 * \mathrm{~B}+0.12 * \mathrm{C}-0.063 * \mathrm{~B} * \mathrm{C}- \\
0.23 * \mathrm{~A}^{2}-0.048 * \mathrm{~B}^{2}-0.11 * \mathrm{C}^{2}
\end{gathered}
$$

In terms of actual factors the final model was as follows:

Yield of Lemongrass (Cymbopogon citratus) Oil, Y:

$$
\mathrm{Y}=-10.56057+1.00046 * \text { Water Ratio + }
$$

$0.044978 *$ Microwave Power Level $+0.044893 *$ Extraction Time $-0.0000841667 *$ Microwave Power*Extraction Time $0.056656 *$ Water Ratio ${ }^{2}-0.0000761228 *$ Microwave Power

$$
\text { Level }^{2}-0.000122146 * \text { Extraction Time }{ }^{2}
$$

This model could be used to predict the yield of Lemongrass (Cymbopogon citratus) oil within the limits of the experiment. The normal probability plot of the residuals and the plot of the residuals versus the predicted response for Lemongrass (Cymbopogon citratus) oil yield were being shown in Figure 6 and 7. A check on the plot in Figure 6 revealed that the residuals generally fell on a straight line implying that errors were being distributed normally, and thus, supported adequacy of the least-square fit. Figure 7 shown that was no obvious pattern and unusual structure. They also showed almost equal scatter above and below x-axis. This implied that the models proposed were adequate and there was no reason to suspect any violation of the independence or constant variance assumption.

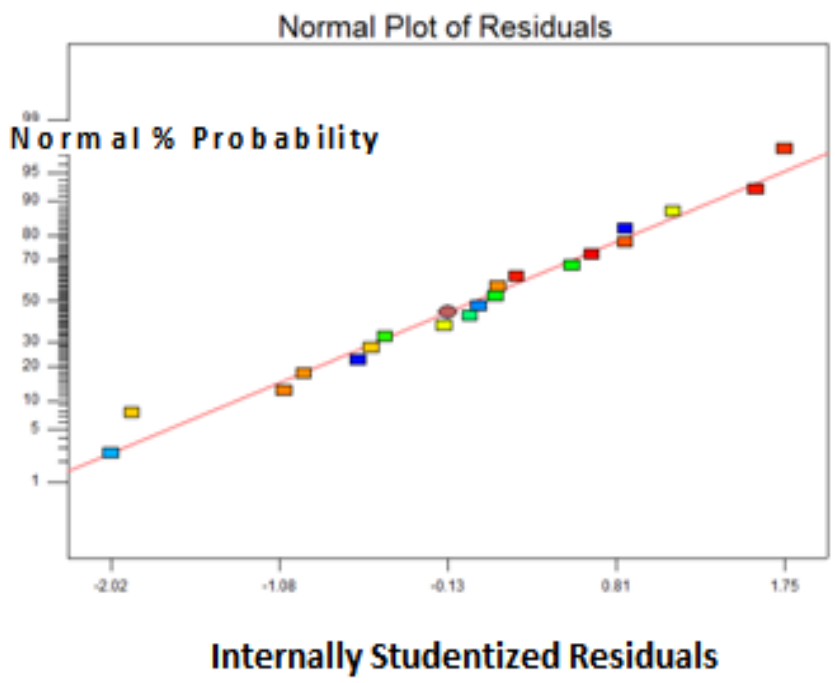

Fig 6: Normal probability plot of residual for yield of Lemongrass (Cymbopogon citratus) Oil 


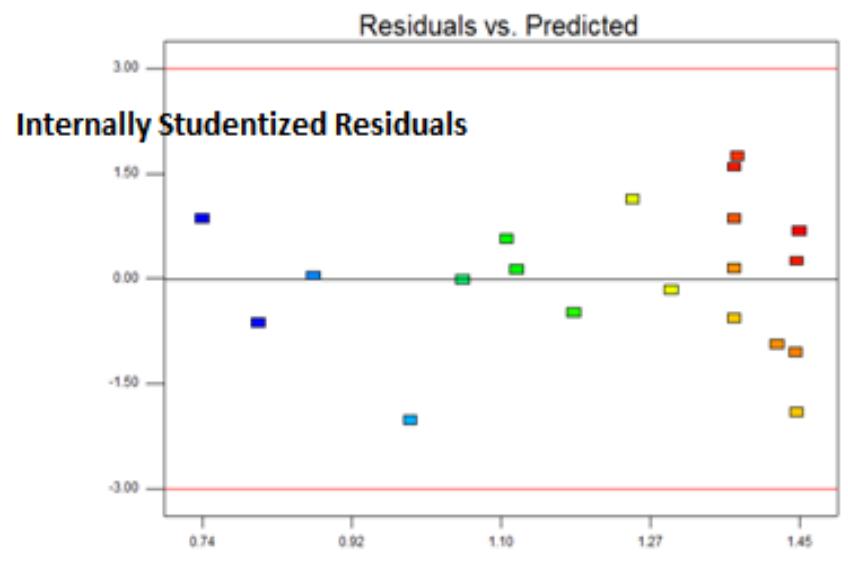

Predicted

Fig 7: Plot of residual vs. predicted response for yield of Lemongrass (Cymbopogon citratus) Oil

Interaction Effect of Process Variables on Lemongrass (Cymbopogon citratus) Oil Production- As the fitted model provides an approximation to the experimental condition; the model was applied to analyze the values of the process variables for maximum yield. The regression equation was being represented graphically in three-dimensional (3D) response surfaces and two-dimensional (2D) contour plots using the statistical software Design-Expert in Figure 8 and 9, respetively. These plots represent the extract yield as a function of the microwave power (B) and extraction time (C) with the water to plant material ratio was selected as center point at 8:1. From the graphs, it shows that the Lemongrass (Cymbopogon citratus) oil yield increased when the microwave power level being increased from 200 watt to 250 watt and the extraction time was being increased from $60 \mathrm{~min}$ to $105 \mathrm{~min}$, and then slightly decreased from $105 \mathrm{~min}$ to 120 min. The maximum Lemongrass (Cymbopogon citratus) oil yield of $1.4612 \%$ was being observed at $90 \mathrm{~min}$ to $105 \mathrm{~min}$ of extraction time and 225 watt to 250 watt microwave power level. The maximum to minimum values of responses based on the interaction of these two factors were also being represented by the color of the 3D surface and contour which is red to green, respectively.

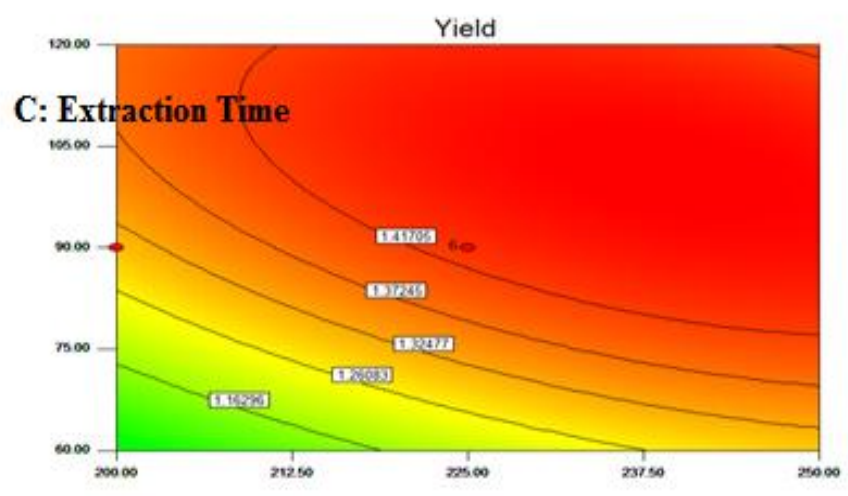

\section{B: Microwave Power Level}

Fig 8: Contour plot on the Lemongrass (Cymbopogon citratus) oil yield of interaction between microwave power level and extraction time

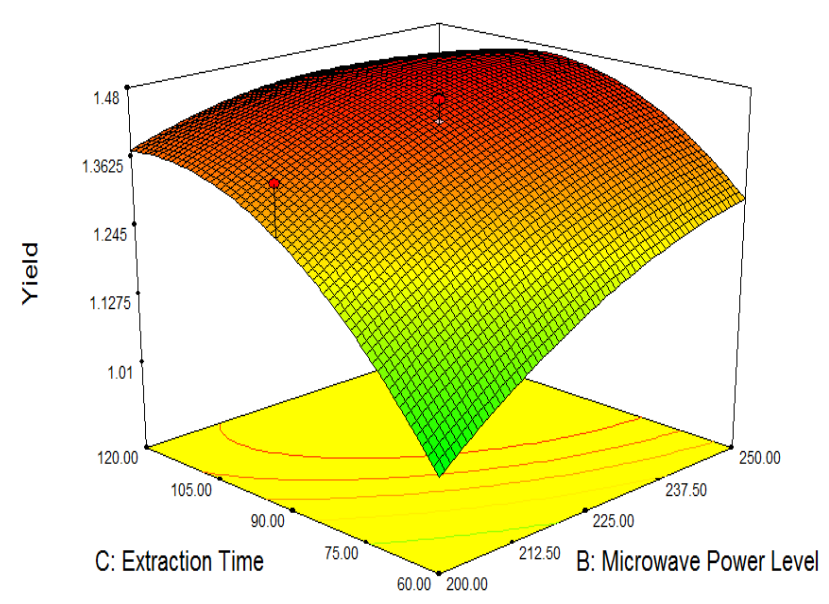

Fig 9: 3D surface on Lemongrass (Cymbopogon citratus) oil Yield of interaction between microwave power level and extraction time

Confirmation Run and Optimal Conditions- By using the numerical optimization of the Design Expert 7.1.6 software based on the model proposed, a solution was generated by the software to determine the optimum condition of the process. The optimum conditions to extract essential oil from Lemongrass (Cymbopogon citratus) were realized when the water to plant material ratio of 8.31:1, microwave power level 240.74 watt, and extraction time about 90 min. By taking into consideration actual operation convenience and extraction condition, those predicted conditions were normalized a water to plant material ratio of $8: 1$, microwave power level $250 \mathrm{~W}$ and extraction time $90 \mathrm{~min}$. According to the result obtained after solving the regression model equation, the highest predicted yield was $1.461188 \%$ at the given conditions above. 
Table 6: Confirmation run of the Lemongrass (Cymbopogon citratus) oil yield

\begin{tabular}{|c|c|c|c|c|c|c|}
\hline $\begin{array}{c}(\mathrm{A}): \\
\text { Water to Plant } \\
\text { Material Ratio }\end{array}$ & $\begin{array}{c}\text { Microwave Power } \\
\text { Level, watt }\end{array}$ & $\begin{array}{c}(\mathrm{C}): \\
\text { Extraction } \\
\text { Time, min }\end{array}$ & $\begin{array}{c}\text { Actual } \\
\text { Value }\end{array}$ & Predicted Value & Residual & Error (\%) \\
\hline $8: 1$ & 250 & 90 & 1.4635 & 1.461188 & 0.0023124 & 0.158001 \\
\hline $6: 1$ & 200 & 60 & 0.58 & 0.597116 & -0.017116 & -2.95103 \\
\hline $10: 1$ & 200 & 60 & 0.89 & 0.972972 & -0.082972 & -9.3227 \\
\hline $6: 1$ & 250 & 120 & 0.9002 & 0.992656 & -0.092456 & -10.2706 \\
\hline $10: 1$ & 250 & 120 & 1.29 & 1.368512 & -0.078512 & -6.08617 \\
\hline $6: 1$ & 250 & 60 & 0.8752 & 0.880753 & -0.005553 & -0.63447 \\
\hline $10: 1$ & 250 & 60 & 1.16 & 1.256609 & -0.096609 & -8.32835 \\
\hline
\end{tabular}

In order to verify the adequacy of the model developed, seven confirmations run together with the predicted optimum condition experiments were being performed, as per listed in Table 6. Then, the comparison between the experimental with the predicted results from the model was made. These validation runs were chosen upon the upper and lower boundary of the optimum parameter configuration. Equation 3 was being used to calculate the predicted value of yields. It can be observed the percentage errors between the actual and predicted value for Lemongrass (Cymbopogon citratus) oil yield were in range of $-10.2706 \%$ to $0.0008 \%$. The yield of Lemongrass (Cymbopogon citratus) oil at optimum conditions shows only $0.158 \%$ of error, thus, the measured value lay within $95 \%$ mean confidence interval of the predicted value for optimum Lemongrass (Cymbopogon citratus) oil. The yield obtained under the proposed economic condition in the laboratory $(1.4635 \%)$ was very close with the predicted one, proved the reliability of the employed model, as well as the success of the RSM in optimizing the extraction conditions.

\section{CONCLUSIONS}

This study was carried out to investigate the MAHD of Lemongrass (Cymbopogon citratus) and optimized the experimental condition by using response surface methodology (RSM) based on central composite design (CCD). The most significant main effect was water to plant material ratio followed by extraction time and microwave power level. The condition predicted by design model for obtained optimum yield of $1.461 \%$ were $8: 1$ water to plant material ratio, $250 \mathrm{~W}$ microwave power level and $90 \mathrm{~min}$ of extraction time. In addition, GC-MS results proved that there were no significant difference between the constituents of essential obtained by MAHD and those obtained by conventional HD. Due to the substantial saving of time, cost and energy with no significant changes in its constituents, MAHD process is a good alternative in the extraction processes of essential oil from Lemongrass (Cymbopogon Citratus).

\section{REFERENCES}

[1] Husnu, K. C. B. and Gerhard, B. 2010. Handbook of Essential Oils: Science, Technology, and Applications. New York: Taylor \& Francis Group.

[2] Tajidin, N. E., Ahmad, S. H., Rosenani, A. B., Azimah, H. and Munirah, M. 2012. Chemical composition and citral content in lemongrass (cymbopogon citratus) essential oil at three maturity stages. African Journal of Biotechnology. 11(11):2685-2693

[3] Chantal, S., Prachakoli, S. and Ruangviriyachai, C. 2012. Influence of extraction methodologies on the analysis of five major volatile aromatic compounds of citronella grass and lemongrass grown in Thailand. Journal of AOAC International. 95:763-772

[4] Carlson, L. H. C., Machad, C. B. S., Pereira, L. K. and Bolzan, A. 2001. Extraction of Lemongrass essential oil with dense carbon dioxide. Journal of Supercritical Fluids. 21:33

[5] Asaolu, M. F., Olyeyemi, O. A. and Olanlokun, J. O. 2009. Chemical compositions, phytochemical constituents and in vitro biological activity of various extracts of cymbopogon citratus. Pakistan Journal of Nutrition. 8(12):1920-1922.

[6] Behboud, J., Amirreza, E., Babak, M. A. and Zarifeh, H. 2012. Antibacterial activities Lemon Grass methanol extract and essence on pathogenic bacteria. American-Eurasia Journal of Agriculture and Environmental Science. 12(8):1042-1046

[7] Nikos, G. T. and Costas, D. E. 2007. Antifungal activity of Lemongrass (Cymbopogon citratus L.) essential oil against key postharvest pathogens. Innovative Food Science and Emerging Technologies. 8:253-258

[8] Abderrahmane, D., Lynda, B. and Brahim, Y. M. 2013. Effect of Extraction Method on Chemical Composition, Antioxidant and Anti-Inflammatory Activities of Essential Oil from the Leaves of Algerian Tetraclinis Articulata (Vahl) Masters. Industrial Crops and Products. 44:32-36 
[9] Hong, W. W., Yan, Q. L., Shou, L. W., Zi, J. Y. and Kuan, L. 2010. Comparison of microwave-assisted hydrodistillation in the extraction of essential oils from mango (Mangifera indica L.) flowers. Molecules. 15:7715-7723

[10] Mohsen, G., Asgar, F., Katayoun, J. and Mahsa, M. 2012. Comparison of ohmic-assisted hydrodistillation with traditional hydrodistillation for the extraction of essential oil from Thymus vulgaris L. Journal of Innovative Food Science and Emerging Technology. 14: 85-91.

[11] Mohammad, H. E., Fereshteh, G. and Soosan, R. 2007. Subcritical water extraction of essential oil from coriander seeds (Coriandrum sativum L.). Journal of Food Enginnering. 80:735-740

[12] Porto, C. D. and Decorti, D. 2009.Ultrasound-assisted extraction coupled with under vacuum distillation of flavor compounds from spearmint (carvone-rich) plants: Comparison with conventional hydrodistillation. Ultrasound Sonochem. 16(6):795-799

[13] Jila, A., Cheshmnaz, K. T., Mohsen, M. and Mahnaz, A. 2012a. Comparison of the microwave-assisted hydrodistillation with the traditional hydrodistillation method in the extraction of essential oils from Ferulago angulate (Schelcht.) Boiss. European Journal of Medicinal Plants. 2(4):324-334

[14] Mohammad, T.G. and Karamatollah, R. 2008. Comparison of microwave-assisted hydrodistillation with traditional hydrodistillation method in the extraction of essential oils from Thymus vulgaris L. Food Chemistry. 109: 925-930.

[15] Myers, R. H. and Montgomery, D. C. 2002. Response Surface Methodology: Process and Product optimization using designed experiments, $2^{\text {nd }}$ ed. New York: John Wiley and Sons.

[16] Huynh, K. P. H., Maridabel, J. Gaspillo, P., Hasika, M., Malaluan, R. and Kawasaki, J. 2008. Essential oil from Lemongrass extracted by supercritical carbon dioxide and stean distillation. The Philippine Agricultural Scientist. 91(1):36-41

[17] Nur, A. A. H., Zaibunnisa, A. H., Halimahton, Z. M. S. and Norashikin, S. 2013. An experimental design approach for the extraction of lemongrass (cymbopogon citratus) oleoresin using pressurized liquid extraction (PLE). International Food Research Journal. 20(1):451-455

[18] Muhammad, H. H., Hasfalina, C. M., Hishamuddin, J. and Zurina, Z. A. 2012. Optimization and kinetics of essential oil extraction from citronella grass by ohmic heated hydrodistillation. International Journal of Chemical Engineering and Applications. 3(3):173-177

[19] Edwin, S. M., Leornard, G. and Elijah, G. 2012. Isolation and Identification of essential oil from Cymbopogon Citratus (Stapf) using GC-MS and FTIR. Chemistry and Material Research. 2(4):13-22
[20] Liu, Y., Yang, L., Zu, Y., Zhao, J., Zhang, Y., Zhang, Z. and Wang, W. 2012. Development of an ILMS method for simultaneous extraction and distillation for determination of proanthocyanidins and essential oil in Cortex cinnamomi. Journal of Food Chemistry. 135:2514-2521.

[21] Lan, S. L., Namhyouck, L., Young, H. K., Chang, H. L., Sang, P. H., Yeo, W. J and Young, E. K. 2013. Optimization of Ultrasonic Extraction of Phenolic Antioxidants from Green Tea Using Response Surface Methodology. Molecules. 18: 13530-13545

[22] Mahaveer, D., Vivekananda, M. and Siva, H. 2009. Optimization of microwave assisted extraction of bioactive flavonolignan-silybinin. Journal of Chemical Metrology. 3(1):13-23

[23] Ferhat, A., Meklati, Y., Smadja, J. and Chemat, F. 2006. An improved microwave Clevenger apparatus for distillation of essential oils from orange peel. Journal of Chromatography A. 1112:121-126

[24] Jila, A., Cheshmnaz, K. T. and Mohsen, M. 2012b. Microwave-assisted hydrodistillation of essential oils from Echinophora playtoba DC. Journal of Medicinal Plants Research. 6(28):4475-4480

[25] Sibel, K., Sedef, N. E., Nural, K., Serpil, S., Gulum, S. and Beste, B. 2012. Microwave-assisted hydrodistillation of essential oil from rosemary. Journal of Food Science and Technology. DOI 101007/s13197-011-0610-y

[26] Beatrice, K. and Philippe, C. 2002. Recent extraction techniques for natural products: Microwave-assisted extraction and pressurized solvent extraction. Phytochemical Analysis. 13:105-113

[27] Mohamed, A. R. H., Sallam, Y. I., El-Leithy, A. S. and Safaa, E. A. 2012. Lemongrass (Cymbopogon citratus) essential oil as affected by drying methods. Annals of Agricultural Science. 57(2):113-116

[28] Xiaofeng, L., Lin, L., Xiaoli, W., Yonggang, W. and Feifan, L. 2013. Optimization of microwave-assisted extraction of total flavonoids extraction from Coreopsis tinctoria by response surface methodology. Journal of Chemical and Pharmaceutical Research. 5(12):454458

[29] Zhu, T., Heo, H. J. and Row, K. H. 2012. Central composite design for optimized extraction of polysaccharides from Undaria pinnatifida. Chemical Research Chinese Universities. 28(4):620-623

[30] Cochran, W. G. and Cox, G. M. 1992. Experimental Designs, $2^{\text {nd }}$ ed. New York: John Wiley and Sons. 